\title{
Nanosecond Transient Absorption of Hydrated Electrons and Reduction of Linear Perfluoroalkyl Acids and Sulfonates.
}

William A. Maza ${ }^{1 *}$, Vanessa M. Breslin², Jeffrey C. Owrutsky ${ }^{1 *}$, Bradford B. Pate ${ }^{1}$, and Albert Epshteyn $^{1 *}$

1 Chemistry Division, U.S. Naval Research Laboratory, Washington, D.C. 20375

2 National Research Council, Chemistry Division, U.S. Naval Research Laboratory, Washington, D.C. 20375

${ }^{*}$ Corresponding author contact information:

E-mail: william.maza@nrl.navy.mil, albert.epshteyn@nrl.navy.mil, jeffrey.owrutsky@nrl.navy.mil 


\section{Materials and Methods}

\section{Materials.}

All chemicals including trifluoroacetic acid (PF2A, Aldrich, 99\%), perfluoropropionic acid (PF3A, Combi-Blocks, 97\%), perfluorobutanoic acid (PF4A, Aldrich, 98\%), perfluoropentanoic acid (PF5A, Aldrich, 97\%), perfluorohexanoic acid (PF6A, Aldrich, >97\%), perfluoroheptanoic acid (PF7A, Aldrich, 99\%), perfluorooctanoic acid (PF8A, Aldrich, 95\%), perfluorononanoic acid (PF9A, Aldrich, 97\%), perfluorobutane sulfonate (PF4S, Aldrich, 98\%), perfluorohexane sulfonate (PF6S, Aldrich, $\geq 98 \%$ ), perfluorooctane sulfonate (PF8S, Aldrich, $\geq 98 \%)$, potassium ferrocyanide trihydrate $\left(\mathrm{K}_{4} \mathrm{Fe}(\mathrm{CN})_{6}\right.$, Aldrich, $\left.\geq 99.95 \%\right)$, potassium ferricyanide $\left(\mathrm{K}_{3} \mathrm{Fe}(\mathrm{CN})_{6}\right.$, Aldrich, $\left.\geq 99.98 \%\right)$, methyl viologen dichloride hydrate $\left(\mathrm{MV}^{2+}\right.$, Aldrich, $\left.98 \%\right)$, potassium nitrate $\left(\mathrm{KNO}_{3}\right.$, Aldrich, $\geq 99.0 \%$ ), and glycine (Alfa Aesar, $\geq 99 \%$ ) were used as received without further purification.

\section{Transient Absorption.}

Transient absorption measurements were carried out on a previously-described home-built system. ${ }^{1}$ Samples were prepared in a $1 \mathrm{~cm}$ quartz cuvette, housed in a Luma 40 Peltier temperature-controlled cuvette holder, and irradiated at $10 \mathrm{~Hz}$ using the fourth harmonic ( $\lambda=266 \mathrm{~nm}, \sim 300 \mu \mathrm{J}, 5-6 \mathrm{~ns}$ pulsewidth) output of a Minilite II Nd:YAG laser (Continuum) and probed collinearly with the excitation using a $670 \mathrm{~nm}$ cw laser diode (Thorlabs CPS670F, $4.5 \mathrm{~mW}$ ). The change in the laser diode intensity was monitored by a Thorlabs balanced Si Photodetector (PDB415A, 100MHz frequency response) and digitized on a Tektronix TBS2204b oscilloscope (200 MHz, $2 \mathrm{GS} / \mathrm{s}$ ). Each transient shown represents the average of $\sim 100$ shots. The transients were converted to absorption and analyzed using the OriginPro software package.

Stock solutions of the corresponding electron scavenger $\mathrm{KNO}_{3}, \mathrm{~K}_{3} \mathrm{Fe}(\mathrm{CN})_{6}$, methyl viologen $\left(\mathrm{MV}^{2+}\right)$, and glycine were prepared in neat deionized water, capped, and sparged with $\mathrm{N}_{2}$ for 10-15 min. PFxA and PFxS stock solutions were prepared at concentrations between $1 \mathrm{mM}$ and $3 \mathrm{mM}$ and titrated to $\mathrm{pH} 10$ with $\mathrm{NaOH}$. These concentrations of the PFAS stock solutions were chosen so that they all remained below the solubility limit of potassium perfluorooctane sulfonate (solubility $<1.3 \mathrm{mM}^{2}$ ) and so that the final concentrations of PFxA and PFxS in the sample solutions probed resembled those concentrations used in degradative studies $(<200 \mu \mathrm{M}))^{3-8}$ No co-solvents were used to increase the concentrations of the PFxA and PFxS stock solutions. Aliquots of the deaerated $\mathrm{e}_{\mathrm{aq}}{ }^{-}$acceptor were added using a glass Hamilton syringe to minimize potential contamination by other fluorinated leachates. The syringe was cleaned by thoroughly rinsing with water and ethanol between experiments.

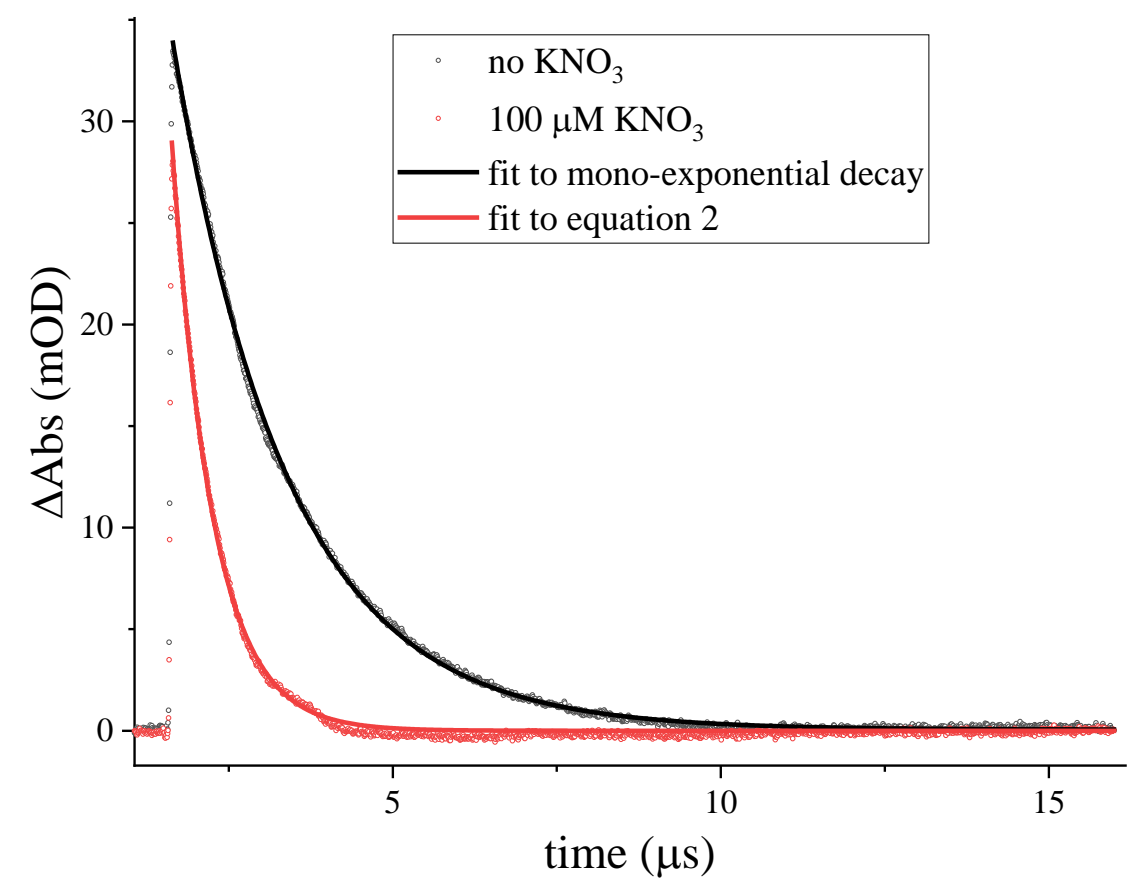

Figure 1. Transient absorption decays obtained at $670 \mathrm{~nm}$ in the absence (black) and presence of $100 \mu \mathrm{M} \mathrm{KNO}$ (red). Solid lines represent non-linear least squares fits to the data using a single exponential decay fit (black line, $\tau_{0}=1.75 \pm 0.01 \mu \mathrm{s}$ ) and equation 2 of the main text (red line, $\tau_{0}$ fixed to $1.75 \mu \mathrm{s}, \Delta \mathrm{A}_{0}=0.028 \pm .001, \mathrm{k}_{\mathrm{q}}=(9.56 \pm 0.04) \times 10^{9} \mathrm{M}^{-1} \mathrm{~s}^{-1}, \mathrm{R}^{2}=0.997$ which is in excellent agreement with the $\mathrm{k}_{\mathrm{q}}$ of $(9.43 \pm 0.19) \times 10^{9} \mathrm{M}^{-1} \mathrm{~s}^{-1}$ obtained from the Stern-Volmer analysis of the concentration dependent data). 

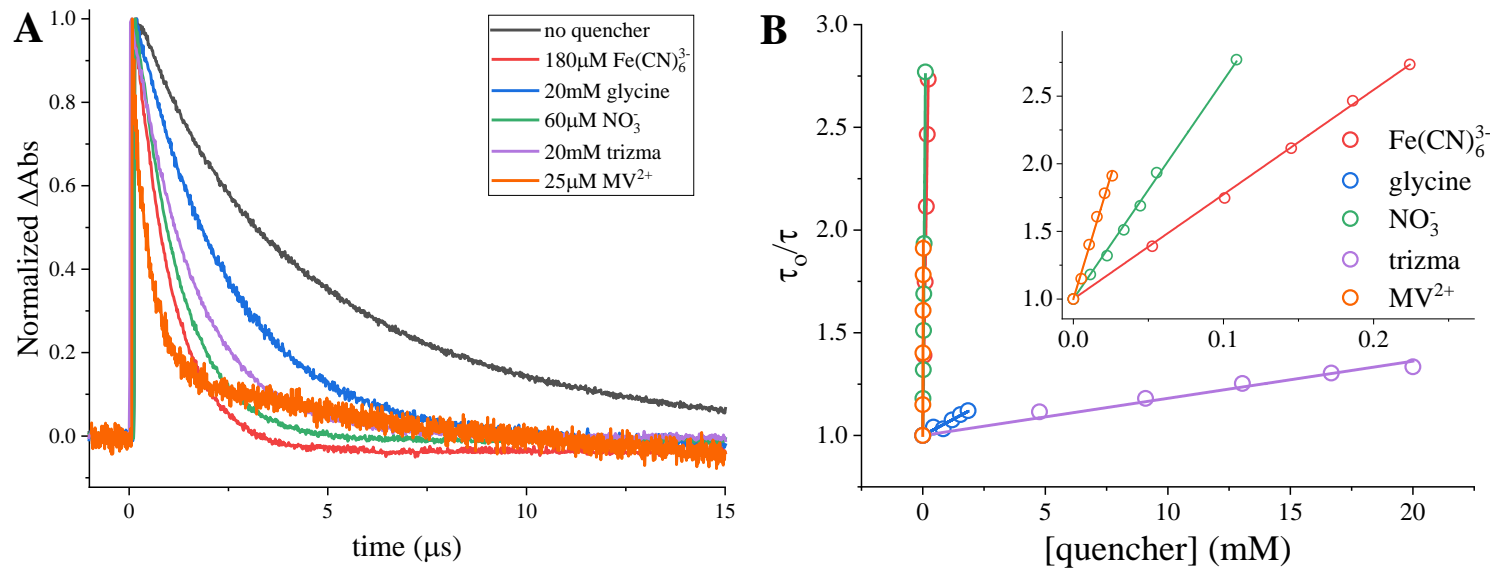

Figure 2. A) The $e_{a q}^{-}$transient decays obtained at $670 \mathrm{~nm}$ in $40 \mu \mathrm{M} \mathrm{K} \mathrm{K}_{4} \mathrm{Fe}(\mathrm{CN})_{6}$ in the absence (black) and presence of $180 \mu \mathrm{M} \mathrm{Fe}(\mathrm{CN})_{6}{ }^{3-}$ (red), $20 \mathrm{mM}$ glycine (blue), $60 \mu \mathrm{M} \mathrm{NO}_{3}{ }^{-}$(green), $20 \mathrm{mM}$ trizma (purple), and $25 \mu \mathrm{M} \mathrm{MV}^{2+}$ (orange). B) SternVolmer plot of the reaction of the $\mathrm{e}_{\mathrm{aq}}{ }^{-}$with $\mathrm{Fe}(\mathrm{CN})_{6}{ }^{3-}$ (red), glycine (blue), $\mathrm{NO}_{3}{ }^{-}$(green), trizma (purple), and $\mathrm{MV}^{2+}$ (orange). Solid lines represent best fits to equation 1 in the text. 
Table 1. Comparison of bimolecular quenching rate constants obtained here and those reported in the literature.

\begin{tabular}{ccc}
\hline Quencher & $\begin{array}{c}\text { Literature value* } \\
\left(\mathrm{M}^{-1} \mathrm{~s}^{-1}\right)\end{array}$ & $\begin{array}{c}\text { Our results } \\
\left(\mathrm{M}^{-1} \mathrm{~s}^{-1}\right)\end{array}$ \\
\hline $\mathrm{NO}_{3}{ }^{-}$ & $(0.66-1.1) \times 10^{10}$ & $(1.1 \pm 0.1) \times 10^{10}$ \\
$\mathrm{MV}^{2+}$ & $(5.5-9.0) \times 10^{10}$ & $(6.9 \pm 0.9) \times 10^{10}$ \\
$\mathrm{Fe}(\mathrm{CN})^{3-}$ & $(2.4-3.7) \times 10^{9}$ & $(4.1 \pm 0.5) \times 10^{9}$ \\
Glycine & $(0.8-1.0) \times 10^{7}$ & $(1.1 \pm 0.2) \times 10^{7}$ \\
Trizma & $\mathrm{N} / \mathrm{A}$ & $(8.6 \pm 0.3) \times 10^{6}$ \\
\hline
\end{tabular}

* Literature values from references ${ }^{9}, \mathrm{NO}_{3}{ }^{-10-12}, \mathrm{MV}^{2+10,13-17}, \mathrm{Fe}(\mathrm{CN})_{6}{ }^{3-18-20}$, and glycine ${ }^{21-23}$.
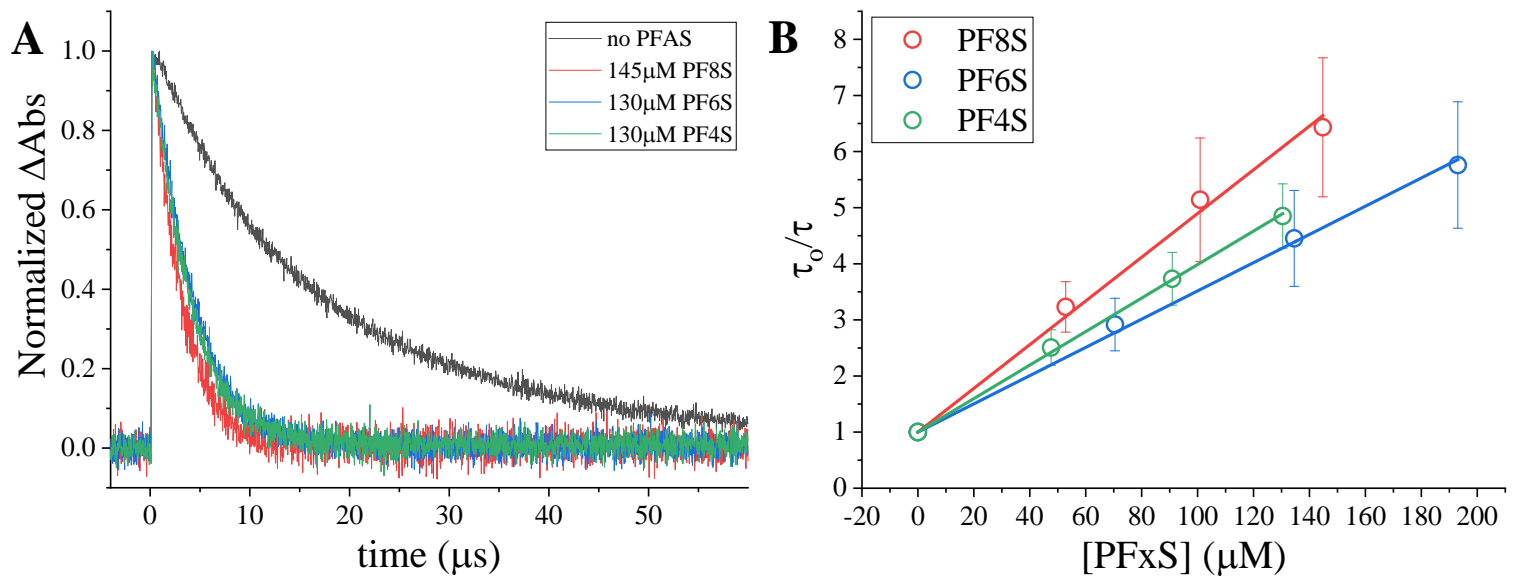

Figure 3. A) Transient absorption $\mathrm{e}_{\mathrm{aq}}{ }^{-}$lifetime decays in neat water (black) and in the presence of $145 \mu \mathrm{M}$ PF8S (red), $130 \mu \mathrm{M}$ PF6S (blue), and $130 \mu \mathrm{M}$ PF4S (green). B) Stern-Volmer plots for the quenching of $\mathrm{e}_{\mathrm{aq}}{ }^{-}$by PF8S (red), PF6S (blue), and PF4S (green). The error bars on each point represent the average of at least three data sets.
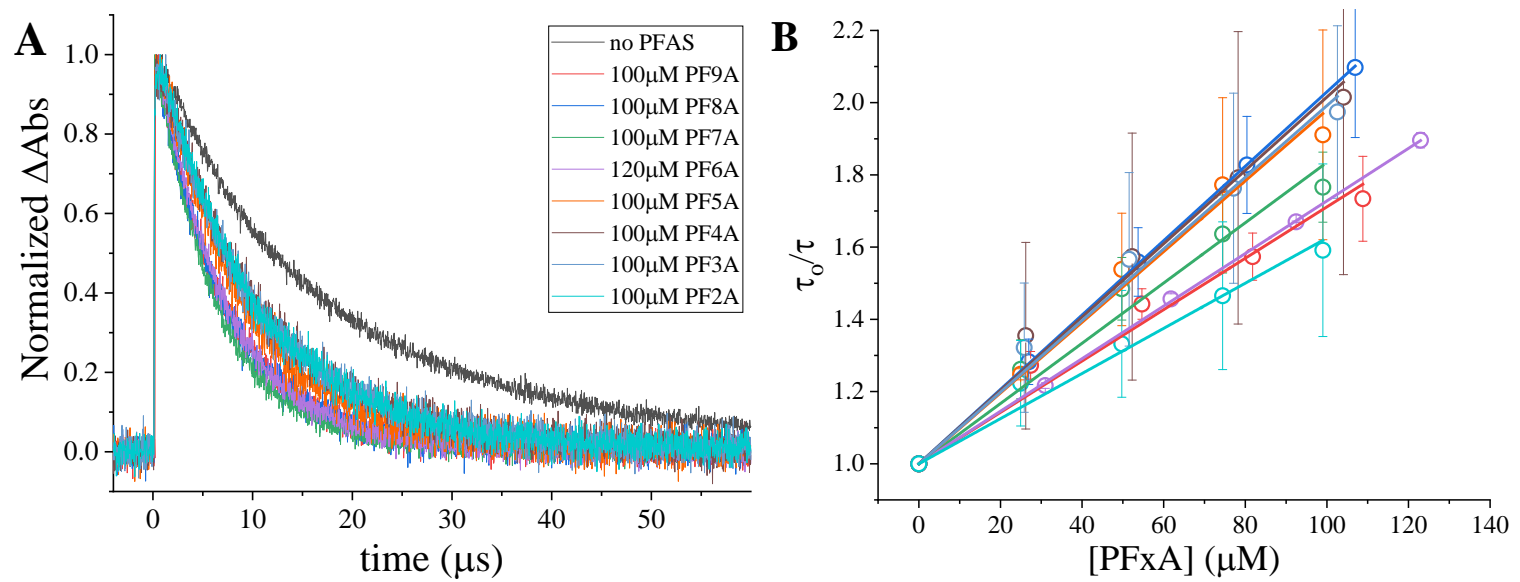

Figure 4. A) Transient absorption $\mathrm{e}_{\mathrm{aq}}{ }^{-}$lifetime decays in neat water (black) and in the presence of $100 \mu \mathrm{M}$ PF9A (red), $100 \mu \mathrm{M}$ PF8A (blue), $100 \mu \mathrm{M}$ PF7A (green), $120 \mu \mathrm{M}$ PF6A (purple), $100 \mu \mathrm{M}$ PF5A (orange), $100 \mu \mathrm{M}$ PF4A (brown), $100 \mu \mathrm{M}$ PF3A (light blue), and $100 \mu \mathrm{M}$ PF2A (cyan). B) Stern-Volmer plots for the quenching of $\mathrm{e}_{\mathrm{aq}}{ }^{-}$by PF9A (red), PF8A (blue), PF7A (green), PF6A (purple), PF5A (orange), PF4A (brown), PF3A (light blue), and PF2A (cyan). The error bars at each point represent the average of at least three sets. 

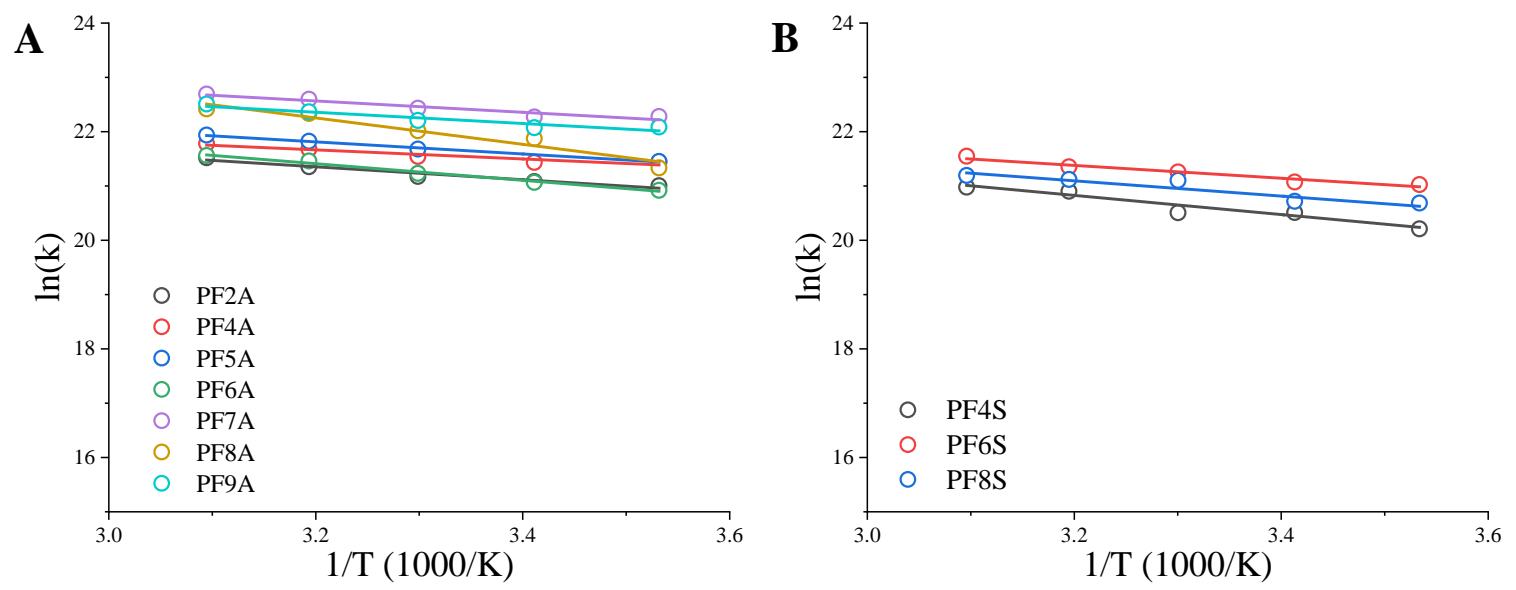

Figure 5. Arrhenius plots for the temperature dependence on the quenching rate constant, $\mathrm{k}_{\mathrm{q}}$, for A) PFxA and B) PFxS.

\section{References:}

1. Maza, W. A.; Breslin, V. M.; Plymale, N. T.; DeSario, P. A.; Epshteyn, A.; Owrutsky, J. C.; Pate, B. B., Nanosecond Transient Absorption Studies of the $\mathrm{pH}$-Dependent Hydrated Electron Quenching by $\mathrm{HSO}_{3}$. Photochem. Photobiol. Sci. 2019, 18, 1526-1532.

2. OECD Hazard assessment of perfluorooctane sulfonate (PFOS) and its salts; 2002; $\mathrm{p} 362$.

3. Song, Z.; Tang, H. Q.; Wang, N.; Zhu, L. H., Reductive Defluorination of Perfluorooctanoic Acid by Hydrated Electrons in a Sulfite-Mediated UV Photochemical System. J. Hazard. Mater. 2013, 262, 332338.

4. $\quad$ Park, H.; Vecitis, C. D.; Cheng, J.; Choi, W.; Mader, B. T.; Hoffmann, M. R., Reductive Defluorination of Aqueous Perfluorinated Alkyl Surfactants: Effects of Ionic Headgroup and Chain Length. J. Phys. Chem. A 2009, 113 (4), 690-696.

5. Qu, Y.; Zhang, C. J.; Chen, P.; Zhou, Q.; Zhang, W. X., Effect of initial solution pH on photoinduced reductive decomposition of perfluorooctanoic acid. Chemosphere 2014, 107, 218-223.

6. Ochoa-Herrera, V.; Sierra-Alvarez, R.; Somogyi, A.; Jacobsen, N. E.; Wysocki, V. H.; Field, J. A., Reductive Defluorination of Perfluorooctane Sulfonate. Environ. Sci. Technol. 2008, 42 (9), 3260-3264.

7. Li, X.; Fang, J.; Liu, G.; Zhang, S.; Pan, B.; Ma, J., Kinetics and efficiency of the hydrated electroninduced dehalogenation by the sulfite/UV process. Water. Res. 2014, 62, 220-228.

8. $\quad$ Bentel, M. J.; Yu, Y.; Xu, L.; Li, Z.; Wong, B. M.; Men, Y.; Liu, J., Defluorination of Per- and Polyfluoroalkyl Substances (PFASs) with Hydrated Electrons: Structural Dependence and Implications to PFAS Remediation and Management. Environ. Sci. Technol. 2019, 53 (7), 3718-3728.

9. Buxton, G. V.; Greenstock, C. L.; Helman, W. P.; Ross, A. B., Critical-Review of Rate Constants for Reactions of Hydrated Electrons, Hydrogen-Atoms and Hydroxyl Radicals $\left(\cdot \mathrm{OH} / \mathrm{O}^{-}\right)$in Aqueous-Solution. J. Phys. Chem. Ref. Data 1988, 17 (2), 513-886.

10. Horvath, A.; Horvath, O.; Stevenson, K. L., Time Resolved Studies of the Photoinduced ElectronTransfer in Aqueous-Solutions of Chlorocuprate(I) and Cyanocuprate(I) Complexes. J Photoch Photobio A 1992, 68 (2), 155-163.

11. Zhestkova, T. P.; Obruch, A. N.; Pikaev, A. K., Radiolysis of Concentrated-Solutions of SodiumNitrate in $\mathrm{D}_{2} \mathrm{O}$. High Energ Chem+ 1992, 26 (5), 329-332.

12. Anbar, M.; Alfassi, Z. B.; Bregmanr.H, Hydrated Electron Reactions in View of Their Temperature Dependence. J. Am. Chem. Soc. 1967, 89 (5), 1263-1264.

13. Elliot, A. J.; Mccracken, D. R.; Buxton, G. V.; Wood, N. D., Estimation of Rate Constants for nearDiffusion-Controlled Reactions in Water at High-Temperatures. J Chem Soc Faraday T 1990, 86 (9), 15391547. 
14. Solar, S.; Solar, W.; Getoff, N.; Holcman, J.; Sehested, K., Pulse radiolysis of methyl viologen in aqueous solutions. Journal of the Chemical Society, Faraday Transactions 1: Physical Chemistry in Condensed Phases 1982, 78 (8), 2467-2477.

15. Rodgers, M. A.; Foyt, D. C.; Zimek, Z. A., The Effect of Surfactant Micelles on the Reaction between Hydrated Electrons and Dimethyl Viologen. Radiat. Res. 1978, 75 (2), 296-304.

16. Patterson, L.; Small Jr, R.; Scaiano, J., Reaction of paraquat radical cations with oxygen: a pulse radiolysis and laser photolysis study. Radiat. Res. 1977, 72 (2), 218-225.

17. Farrington, J.; Ebert, M.; Land, E. J.; Fletcher, K., Bipyridylium quaternary salts and related compounds. V. Pulse radiolysis studies of the reaction of paraquat radical with oxygen. Implications for the mode of action of bipyridyl herbicides. Biochimica et Biophysica Acta (BBA)-Bioenergetics 1973, 314 (3), 372-381.

18. Zehavi, D.; Rabani, J., Pulse radiolysis of the aqueous ferro-ferricyanide system. II. Reactions of hydrogen atoms and hydrated electrons with ferrocyanide and ferricyanide ions. J. Phys. Chem. 1974, 78 (14), 1368-1373.

19. Hankiewicz, E.; Schulte-Frohlinde, D., The rate of hydrated electron reaction with neutral and anionic scavengers in concentrated salt solutions. J. Phys. Chem. 1977, 81 (26), 2614-2618.

20. Duplatre, G.; Jonah, C. D., Reactions of Electrons in High-Concentration Water Solutions - a Comparison between Pulse-Radiolysis and Positron-Annihilation Lifetime Spectroscopy Data. Radiat. Phys. Chem. 1984, 24 (5-6), 557-565.

21. Braams, R., Rate constants of hydrated electron reactions with amino acids. Radiat. Res. 1966, 27 (3), 319-329.

22. Hayon, E.; Simic, M., Free radical intermediates produced in the pulse radiolysis of simple peptides in aqueous solution. Intra-Science Chemistry Reports 1971, 5, 357-369.

23. Peter, F. A.; Neta, P., Effect of ionic dissociation of organic compounds on their rate of reaction with hydrated electrons. J. Phys. Chem. 1972, 76 (5), 630-635. 